\title{
OS SENTIDOS FORMATIVOS DAS CONCEPÇÕES DE CORPO E EXISTÊNCIA NA FENOMENOLOGIA DE MERLEAU-PONTY
}

\author{
Formative Conceptions of the Senses of Body and Existence in Merleau-Ponty's Phenomenology \\ Concepciones Formativas de los Sentidos de Cuerpo y Existéncia en la Fenomenología \\ de Merleau-Ponty
}

AdÃo José Peixoto

\begin{abstract}
Resumo: O artigo é uma reflexão sobre os sentidos formativos das concepções de corpo e existência na fenomenologia de Merleau-Ponty. Tomamos como referencial teórico as contribuições da fenomenologia da percepção na perspectiva apresentada por este filósofo. Neste sentido, o texto é um esforço para pensar o corpo enquanto totalidade dialética da existência humana, visando superar as concepções que dicotomizam a relação corpo-consciência.

Palavras-chave: Corpo; Existência; Fenomenologia.
\end{abstract}

Abstract: The article is a reflection about the body and existence sense and its formative dimension. We considered the contributions of the phenomenology of the perception in the perspective, presented by Merleau-Ponty, as the theoretical referential. In that sense, he tries to think the body while dialectic totality of the human existence, aiming to overcome the conceptions that dichotomyze the relation body-conscience.

Keywords: Body; Existence; Phenomenology.

Resumen: El artículo es una reflexión sobre los significados de los conceptos de formación del cuerpo y la presencia en la fenomenología Merleau-Ponty. Tomamos como aportaciones teóricas de la fenomenología de la percepción de la perspectiva presentada por el filósofo. En este sentido, el texto es un esfuerzo por pensar el cuerpo como toda una dialéctica de la existencia humana con el fin de abandonar la dicotomía de ideas que la relación entre la conciencia del cuerpo.

Palabras-clave: Cuerpo; Existencia; Fenomenología.

\section{Introdução}

O que propomos neste texto é apresentar uma reflexão sobre o sentido do corpo e da existência e sua dimensão formativa com base nas contribuições da fenomenologia da percepção de Merleau-Ponty. Tomamos como ponto de partida a reflexão sobre o conceito de intencionalidade, formulado por Husserl, e a sua influência no pensamento de Merleau-Ponty. Em seguida, abordaremos as concepções de corpo e existência e sua dimensão formativa.

Acreditamos que pensar o corpo e suas diversas formas de ser-no-mundo é um desafio de pensar o homem como totalidade da existência humana; de superar a dicotomia que historicamente tem caracterizado o homem em polos opostos - de um lado o que valoriza só a consciência, a herança racionalista, e, de outro, só os aspectos fisiológicos do corpo, os sentidos, a herança empirista; de colocar o corpo como uma das centralidades do pensar e da prática humana.

\section{A Influência de Husserl no Pensamento de Merle- au-Ponty}

A fenomenologia é o estudo dos fenômenos. Entendemse por fenômenos (Peixoto, 2003): todas as coisas materiais que percebemos e tocamos; as coisas naturais estudadas pelas ciências da natureza (física, química, astronomia, biologia...); as coisas ideais, aquilo que é estudado pela matemática (números, figuras geométricas, conceitos como identidade, necessidade...), e as coisas criadas pela cultura, pela ação e prática humanas (crenças, valores morais, artes, técnicas, instituições sociais e políticas). Não há uma identidade entre fenômeno e ente, o fenômeno é a própria correlação, é a "consciência de", isto é, a vivência fenomenológica de todo ser, daí "significações e essências”. A árvore que eu percebo, por exemplo, é um fenômeno como árvore percebida, mas nem por isso deixa de ser árvore. Daí, a fenomenologia não ser o estudo da árvore (como ente), mas pode ser da árvore percebida, ou seja, do ato de perceber um ente, no caso, a árvore tal como se manifesta. O mesmo ocorreria para a árvore fantasiada, imaginada, sonhada, desejada etc. Todas es- 
sas coisas são vivenciadas como fenômenos, isto é, significações ou essências (eidos) que aparecem à consciência. Portanto, a fenomenologia é o estudo de todas as essências ou significações de todas as realidades, sejam materiais, naturais, ideais e culturais e, portanto, de todos os fenômenos.

Edmund Husserl elaborou os fundamentos da fenomenologia num contexto (final do século XIX e início do século XX) de profundas mudanças intelectuais e de difusão das ciências humanas. Este contexto foi de grande influência para a dicotomia corpo/alma, sujeito/objeto, consciência/mundo, estabelecida de um lado pelo racionalismo e, de outro, pelo empirismo. Também predominou neste a crença positivista no cientificismo, crença que acredita ser a ciência a solução para todos os problemas da humanidade; e crença de que todo conhecimento para ser científico precisa ser neutro.

O racionalismo afirmava que o conhecimento verdadeiro é o que surge do sujeito. Descartes elegeu a dúvida como método e submeteu tudo ao seu crivo. Entretanto, "o cogito resiste ao esforço universal da dúvida, evidenciandose, por isso, como fundamento primordial" (Zilles, 2003, p. 135). Chega-se à conclusão do Cogito, ergo sum, Penso, logo existo. Esse Cogito é puro pensamento, uma res cogitans (coisa pensante), e o mundo é res extensa (coisa material), sempre suscetível à dúvida. Descartes acredita na existência das ideias inatas, ideias que têm sua origem na razão e são independentes dos sentidos. São inatas porque são resultantes da capacidade do homem de pensar, compreender, interpretar e transformar o próprio homem e as coisas. O critério da verdade é, portanto, a razão.

De acordo com o empirismo, a fonte confiável do conhecimento é a experiência. Parte do princípio de que todas as nossas ideias são cópias de nossas impressões, isto é, dos dados empíricos - impressões de sensação, mas também impressões de reflexão (emoções e paixões). Para Hume, por exemplo, o conhecimento é sempre probabilístico. A sua certeza depende das verificações empíricas a serem feitas. Nesse sentido, as ideias se originam da experiência. Com isso, rejeita a concepção racionalista da identidade individual da consciência. Se as ideias se originam na experiência, nos sentidos, o conteúdo da nossa consciência varia de um momento para o outro.

Para o positivismo, o conhecimento verdadeiro é o conhecimento neutro, objetivo e empiricamente comprovado. É neutro porque o conhecimento, para ser considerado verdadeiro, não pode ter a influência da subjetividade. Os próprios fenômenos sociais devem ser tratados como física social; é objetivo porque se refere aos dados imediatos da experiência, em oposição à metafísica; é empiricamente comprovado porque é o que pode ser testado, medido, quantificável. Assim, o conhecimento científico é o que se caracteriza pela certeza sensível de uma observação sistemática; relaciona os fenômenos a princípios que permitem combinar as observações isoladas; investiga os fenômenos procurando suas relações constantes de concomitância e sucessão, suas leis; é capaz de prever e controlar fenômenos para a instituição de um estado científico.

Para Husserl, a influência do racionalismo, empirismo e positivismo nas ciências humanas e na filosofia não determina a especificidade do objeto destas áreas do conhecimento, tratando-o como um objeto físico, confundindo as causas exteriores de um fenômeno com a própria natureza. É o caso, por exemplo, da psicologia daquela época. Sua crítica deve-se ao fato de esta assumir como método o método das ciências da natureza e aplicá-lo sem levar em conta a sua especificidade. O objeto das ciências humanas - e da psicologia em especial - são os fatos sociais e psíquicos. Portanto, a metodologia a ser aplicada não pode ser a mesma aplicada nas ciências naturais.

A crítica é também endereçada à filosofia, que cometia, segundo Husserl, o erro de tomar como ponto de partida as concepções preestabelecidas, os conceitos já formados, e não os fenômenos como eles são de fato. É por isso que a filosofia tem construído concepções abstratas, desvinculadas da realidade. Para superar essa postura epistemológica, Husserl propõe o conceito de redução eidética, que é o ato da consciência de voltar-se para o próprio fenômeno, e não para as suas interpretações. $\mathrm{O}$ que se propõe é descrever a essência ou a estrutura do fenômeno. Para isso, o procedimento é "ir-à-coisa-mesma", revelar o seu estado primitivo, estado antepredicativo, ainda não tematizado. Com esse procedimento, Husserl quer mostrar-nos que a fenomenologia visa descrever o irrefletido, o mundo vivido, o mundo como tal, como ele é de fato, sem as mediações teóricas. Com a redução eidética, a preocupação é colocar a descoberto o ser da coisa, e não entendida como um mero etifenômeno. Husserl demonstrou que a preocupação da filosofia deve ser com o rigor, e não com a exatidão. Com isso, estabeleceu a diferença entre ciências empíricas, que trabalham com fatos, das ciências eidéticas ou ciências puras, que se ocupam com idealidades. A exatidão é própria das ciências empíricas e busca a abstração do tipo matemático, que possibilita chegar sem equívoco ao resultado pretendido. É um resultado calculado, comprovado, exato. O rigor é próprio das ciências descritivas ou eidéticas. A fenomenologia como ciência eidética que se ocupa da descrição das vivências, dos atos e correlatos da consciência é, por natureza, inexata. A sua preocupação é com o rigor, com a fidelidade ao real, superando os preconceitos, as aparências, o imediatismo. Essa inexatidão é em função da própria natureza do objeto da filosofia, o mundo humano, que é complexo, plural e inconcluso. Por isso, não pode ser tratado em termos de causa e efeito. Nesse sentido, para Husserl, a autêntica filosofia é a fenomenologia.

Com o conceito de redução eidética, Husserl procura indicar a especificidade das ciências naturais e das ciências humanas. Depois, elabora o conceito de intencionalidade, que está intimamente relacionado com o da redução eidética, que procura superar a dicotomia sujeito/objeto, 
consciência/mundo, instituída pelo racionalismo e pelo empirismo, assim como também busca superar a ideia de neutralidade, naturalização das ciências humanas e crença no cientificismo, introduzida pelo positivismo.

A redução eidética representa a ruptura entre a consciência e o cogitatum, e impede que a consciência se enclausure no mundo do pensamento, possibilitando que ela seja abertura para o mundo. $\mathrm{O}$ ponto de partida passa a ser o mundo, e não o pensamento. A redução torna-se o "retorno a uma consciência transcendental diante da qual o mundo se desdobra em uma transparência absoluta" (Zilles, 2003, p. 7). É por isso que toda redução, "ao mesmo tempo em que é transcendental, é necessariamente eidética" (Merleau-Ponty, 1945/1999, p. 11).

Para Husserl, toda consciência é consciência de alguma coisa, é consciência de. Não existe pura consciência, como também não existe mundo sem a consciência. $\mathrm{O}$ ponto de partida é o da vivência imediata da consciência. Com isso, Husserl quer dizer que "a consciência não é uma substância (alma), mas uma atividade constituída por atos (percepção, imaginação, volição, paixão etc.) com os quais visa algo" (Zilles, 2003, p. 172).

A intencionalidade é um transcender, um dirigir-se à outra coisa que não seja a própria consciência. Por isso é vivência, é consciência e mundo. Se é vivência, o que é essa vivência? É toda visada ou ato de visar da consciência e seus correlatos. A todo conteúdo visado, a todo objeto (noema), há a correspondência de uma certa modalidade de consciência (noesis). A intencionalidade institui uma interação entre sujeito e objeto, o homem e o mundo, o pensamento e o ser, mostrando que todos os atos psíquicos, tudo o que acontece na mente, visam a um objeto, $\mathrm{e}$ nada ocorre no vazio. É por isso que Husserl afirma que "todo o estado de consciência em geral é, em si mesmo, consciência de qualquer coisa" (Husserl, 1929/2001, p. 50). Dessa forma, intencionalidade "não significa nada mais que essa particularidade fundamental e geral que a consciência tem de ser consciência de alguma coisa, de conter, em sua qualidade de cogito, seu cogitatum em si mesma" (Husserl, 1929/2001, p. 51). O objeto, por sua vez, só pode ser definido em sua interação com a consciência, por ser sempre objeto-para-um-sujeito. Contrariamente ao que afirma o empirismo, a fenomenologia diz que o objeto só possui sentido para uma consciência. "Assim as essências não existem fora do ato de consciência. Nesse sentido a fenomenologia husserliana busca a descrição dos atos intencionais da consciência e dos objetos por ela visados, ou seja, pela análise noético-noemático" (Zilles, 2003, p. 173).

Para a fenomenologia, a consciência que o homem tem do mundo é mais ampla que o simples conhecimento racional ou empírico, porque ela é fonte de intencionalidades, tanto cognitivas quanto afetivas e práticas. $\mathrm{O}$ olhar do homem sobre o mundo é um ato pelo qual ele o experiencia, imaginando-o, percebendo-o, interpretando-o, compreendendo-o e transformando-o. Aqui, homem-mundo, consciência-objeto são reunidos dialeti- camente numa mesma estrutura. Husserl procurou, com esse conceito, integrar idealismo e empirismo, subjetividade e objetividade.

A intencionalidade corresponde à correlação consciência-mundo, "é visada de consciência e produção de um sentido que permite perceber os fenômenos humanos em seu teor vivido" (Zilles, 2003, p. 171). Dizer que a consciência é intencional significa dizer que ela só pode ser analisada em termos de sentido. Por isso, podemos dizer que a consciência não é uma coisa, mas o que dá sentido às coisas: "o sentido não se constata à maneira de uma coisa, mas se interpreta. É a consciência intencional que faz o mundo aparecer como fenômeno, como significação, pelo fato de ser um cogitatum intencionado pelo sujeito" (Zilles, 2003, p. 173).

O cogito não é mais a operação de um sujeito fechado em si mesmo, mas aberto ao mundo: o verdadeiro cogito não define a existência do sujeito pelo pensamento de existir que ele tem, não converte a certeza do mundo em certeza do pensamento do mundo e, enfim, não substitui o próprio mundo pela significação mundo. Ele reconhece, ao contrário, meu próprio pensamento como um fato inalienável, e elimina qualquer espécie de idealismo revelando-me como "ser no mundo":

(...) o verdadeiro cogito não define a existência do sujeito pelo pensamento de existir que ele tem, não converte a certeza do mundo em certeza do pensamento do mundo e, enfim, não substitui o próprio mundo pela significação do mundo. Ele reconhece, ao contrário, meu próprio pensamento como um fato inalienável, e elimina qualquer espécie de idealismo revelando-me como "ser no mundo" (Merleau-Ponty, 1945/1999, p. 9).

Segundo Merleau-Ponty (1945/1999, p. 15), a intencionalidade é "freqüentemente citada como a principal descoberta da fenomenologia". Parece que essa é também a própria avaliação de Merleau-Ponty (1945/1999, p. 16), em função da importância que ele dá a essa categoria, tanto que considera que com ela a "fenomenologia pode tornarse uma fenomenologia da gênese", da origem e do sentido das coisas. Com a intencionalidade, a fenomenologia pode captar não o sentido da razão ou do objeto isoladamente, mas o sentido que aparece na intersecção de minhas vivências, da intersecção do eu com o mundo․ Mesmo

\footnotetext{
É polêmica a crítica de Merleau-Ponty à concepção de intencionalidade de Husserl. Para ele, há em Husserl duas concepções de intencionalidade: a intencionalidade temática (eu tenho consciência de algo e sei que tenho consciência deste algo) e a intencionalidade operante (eu tenho consciência de algo de modo vivenciado, sem que haja uma consciência tética dando-se conta disto, tenho consciência da distância que separa meu corpo dos objetos, por exemplo, sem que precise pensar sobre isso, fazer cálculos...). A primeira ainda possuía um aspecto idealista, por isso Merleau-Ponty assimila apenas a intencionalidade operante, ou seja, a intencionalidade corporal. Diferentemente de Husserl, Merleau-Ponty une consciência intencional e experiência, ou seja, fenômeno e corpo. Portanto, quando fizermos referência ao conceito de intencionalidade em Merleau-Ponty estaremos entendendo-o nesta perspectiva.
} 
porque "o mundo fenomenológico é não o ser puro, mas o sentido que transparece na intersecção de minhas experiências, e na intersecção de minhas experiências com aquelas do outro, pela engrenagem de umas nas outras" (Merleau-Ponty, 1945/1999, p. 18). Com esse conceito, a fenomenologia procurou superar não só a dicotomia sujeito/objeto, consciência/mundo, mas também a dicotomia corpo/espírito, descobrindo aí relações de reciprocidade. É essa concepção que irá nortear todo o pensamento de Merleau-Ponty, em especial sobre o corpo.

Em oposição ao positivismo, a fenomenologia afirma que não há fatos com a objetividade advogada, já que não percebemos o mundo como um dado bruto, destituído de significados. O mundo que percebo é um mundo para mim. Daí a importância que a fenomenologia dá ao sentido, à rede de significações que envolvem os objetos percebidos. É neste sentido que a consciência é doadora de sentido.

Para a psicologia de orientação positivista e empirista, trata-se de desconsiderar o comportamento da pessoa e substituí-lo por outro socialmente mais aceitável. Já a fenomenologia considera que não se trata de desconsiderar. O comportamento não é, ele significa. É pela emoção que a pessoa se exprime na totalidade do seu ser. Por isso, o comportamento precisa ser interpretado. A relação mecânica do estímulo-resposta não apreende o sentido do comportamento humano. A essa relação, a fenomenologia contrapõe a relação entre o sinal e o símbolo. O sinal faz parte do mundo físico e o símbolo é parte integrante do mundo humano do sentido. É essa relação que devemos compreender.

Para Merleau-Ponty (1945/1999, p. 18), “a aquisição mais importante da fenomenologia foi sem dúvida ter unido o extremo subjetivismo ao extremo objetivismo em sua noção do mundo e da racionalidade. A racionalidade é exatamente proporcional às experiências nas quais ela se revela".

Os conceitos de intencionalidade e redução eidética exerceram grande influência no pensamento de MerleauPonty, principalmente na sua concepção sobre o corpo e a existência. Com o conceito de intencionalidade, MerleauPonty procurou superar a dicotomia corpo/alma instituída pelo racionalismo, empirismo e positivismo. Já com o conceito de redução eidética, procurou compreender a existência humana na sua tessitura com o mundo.

\section{A Concepção de Corpo no Pensamento de Merleau- Ponty}

Para Merleau-Ponty (Peixoto, 2011), o corpo não é uma coisa, não é uma máquina, nem é pura ideia, mas movimento, sensibilidade e expressão criadora. É uma concepção que se opõe às perspectivas racionalistas, empiristas e positivistas.

Vimos que Descartes elabora sua concepção epistemológica com base na dúvida ao transformá-la em método.
É a partir daí que elabora também sua abordagem sobre o corpo. Define-o como pura exterioridade, uma substância extensa, material. Considera que o ser humano é constituído por duas substâncias distintas: a substância pensante, de natureza espiritual, que é o pensamento; e a substância extensa, de natureza material, que é o corpo. Mantém, com isso, o dualismo psicofísico instituído por Platão. Difere deste porque trata o corpo como corpo-objeto, associado à ideia mecanicista do ser humanomáquina. Platão defende o pressuposto de que a alma, antes de ser introduzida no corpo, teria vivido no mundo puramente espiritual, mundo perfeito, mundo das ideias. Ao se unir ao corpo, ela se degrada, vindo a ter influência do mundo dos sentidos. Com isso, ela passa a ter duas dimensões: uma superior (a alma intelectiva) e outra inferior (a alma do corpo). Esta última é irracional e está dividida em duas partes: a irascível, que é impulsiva, localizada no peito; e a concupiscível, centrada no ventre e voltada para os desejos de bens materiais e apetite sexual. Todo esforço humano consiste em exercer o domínio da alma superior sobre a inferior. Como está apegada ao mundo dos sentidos, a alma inferior conduz ao erro, à opinião, à aparência, impedindo o acesso da pessoa à verdade. O corpo, movido pela alma irascível, é fonte de corrupção, de erros e de decadência. Se a alma superior não conseguir dominar as paixões, os desejos, enfim, os apetites do corpo, a pessoa não é capaz de uma existência digna. A alma é eterna, pura, fonte da verdade, e o corpo é mortal, impuro, degradante, fonte do erro, da perdição. Surge aí o dualismo psicofísico, a oposição entre corpo/alma.

O empirismo, por sua vez, reforça esse dualismo, já que reduz a dimensão corpórea às forças deterministas da natureza. Com isso, a pessoa deixa de ser a responsável pelo seu próprio destino, passando a ser determinada pelo meio, pelo momento, pela raça. Essa é também a concepção do positivismo que privilegia apenas a exterioridade do comportamento, a forma como ele se manifesta.

Com o conceito de intencionalidade, Merleau-Ponty supera o dualismo corpo/alma, procurando compreender nesses polos as relações de reciprocidade. Acredita que é na dinâmica entre essas polaridades que pode ser encontrado o sentido tanto do corpo quanto da alma. É na relação do "extremo subjetivismo" com o "extremo objetivismo" que apreendemos a concepção de homem numa perspectiva de totalidade sempre aberta, em circularidade, uma dialética que "mantém a oposição mas não realiza a superação através de uma síntese. Chamada de hiperdialética ou dialética sem síntese, tem como modelo a constante tensão entre polaridades, a constituição de uma latência entre pólos" (Coelho Jr. \& Carmo, 1991, p. 17). Não é nos polos, mas no entre, na mediação, que devemos buscar o sentido das coisas. Nesse sentido, o corpo não se identifica com as coisas, mas é ser-no-mundo. Para Merleau-Ponty (1945/1999, p. 576): 
(...) o mundo é inseparável do sujeito, mas de um sujeito que não é senão projeto do mundo, e o sujeito é inseparável do mundo, mas de um mundo que ele mesmo projeta. O sujeito é ser-no-mundo, e o mundo permanece "subjetivo", já que sua textura e suas articulações são desenhadas pelo movimento de transcendência do sujeito.

O corpo não é coisa e nem obstáculo, mas dimensão da totalidade do ser humano. O meu corpo não é uma coisa que eu possuo. Eu sou meu corpo. Sobre isso, Merleau-Ponty (1945/1999, p. 207-208) afirma: “eu não estou diante do meu corpo, estou em meu corpo, ou antes, sou meu corpo". Eu me revelo pelas minhas manifestações corporais. É por isso que, ao observarmos o movimento de alguém, por exemplo, não percebo como uma simples coisa em movimento, como simples movimento mecânico, como uma máquina, mas como gesto expressivo, o que possibilita a expressão da unidade entre pensamento e ação, entre a dimensão física e psíquica. $\mathrm{O}$ agir aqui tem seu pensamento, não é agir mecânico, destituído de sentido, mas fonte de significação. Assim, o gesto nunca é movimento de uma coisa, não é expressão apenas corporal, mas expressão de uma pessoa; é comunicação que revela a interioridade da pessoa. A expressão facial pode revelar desprezo, raiva, amor, acolhida, rejeição. $\mathrm{O}$ meu corpo e o corpo do outro não é uma coisa qualquer; é corpo humano. Nossa primeira comunicação com os outros e com o mundo quando nascemos é pelo corpo: gestos que revelam que estamos com dor, fome, frio. Antes de sermos um ser que conhece, somos um ser que vive e sente.

É com o corpo que participamos de todas as atividades de nossa vida: do trabalho, do lazer, do sexo, da arte. O trabalho humano, por exemplo, é o processo por meio do qual interferimos e modificamos a natureza, adequando-a às nossas necessidades. Isso é feito não só pela força física, pela ação do corpo, mas também pela ação do pensamento que projeta e orienta a ação do corpo. Com isso, ao mesmo tempo em que transformamos a natureza nos transformamos também.

Podemos dizer que a obra Fenomenologia da percepção apresenta uma reflexão filosófica do "enraizamento da consciência no corpo". A intencionalidade aqui deixa de ser um atributo da consciência para ser expressão de um corpo voltado para o mundo. É por isso que Merleau-Ponty (1945/1999, p. XII) afirma que a "verdade não habita o 'homem interior', ou antes, não há homem interior; o homem está no mundo, e é no mundo que ele se reconhece".

Nessa perspectiva, o corpo percebe e é simultaneamente percebido. O corpo passa a ser nosso "ancoradouro no mundo" (Merleau-Ponty, 1945/1999, p. 200); não é mais um receptáculo passivo das coisas que o rodeiam, mas realidade que exerce uma comunicação com o mundo. É por isso que "o mundo é não aquilo que eu penso, mas aquilo que eu vivo; eu estou aberto ao mundo, comunico-me indubitavelmente com ele, mas não o possuo, ele é inesgotável" (Merleau-Ponty, 1945/1999, p. 14).

Merleau-Ponty desenvolve uma reflexão que traz à luz o que está antes de toda ciência: o mundo vivido. Com isso, ele não está propondo rejeitar a ciência em virtude do seu caráter objetivista, nem cair no irracionalismo. Propõe, isto sim, repensar os seus fundamentos. Ao propor esse voltar-se para o mundo vivido, está defendendo que as ciências e a própria filosofia passam a ter como referência o homem.

O corpo exerce um papel de mediação entre nós e o mundo; ele é natureza e, ao mesmo tempo, cultura. É natureza porque é oriundo do mesmo tecido das coisas do mundo natural e está submetido às suas forças, mas também possui forças para transcendê-las. Por ter condições de transcendência, o corpo é também cultura, já que ultrapassa a fronteira do animal, do natural, e constrói outra ordem, a simbólica, criando a cultura. É por isso que o corpo deixa de ser visto como mero mecanismo biológico, uma mera soma de manifestações causais, para ser visto como expressão de sentidos. O corpo, assim entendido, não é mera passividade, inércia, determinismo, mas mediação com os outros e com o mundo. É nesse sentido que Merleau-Ponty (1945/1999, p. 3) é enfático ao afirmar: "eu não sou o resultado ou entrecruzamento de múltiplas causalidades que determinam meu corpo".

A interrogação filosófica empreendida por MerleauPonty procura dar ênfase à experiência vivida, à noção de comportamento, que possui a mesma noção de existência. Esse procedimento supera o clássico dualismo entre o psíquico e o físico. Nosso corpo é inserção no mundo real, mas também no mundo imaginário. Ele possibilita comportamentos inteligentes. O hábito, por exemplo, não está nem no pensamento, como mera representação mental, nem no corpo-objeto, mas no corpo como mediador do mundo.

É pela experiência do corpo no mundo que eu me insiro no mundo. Ao dizer que "sou meu corpo", MerleauPonty dissolve o problema da dicotomia corpo/espírito e passa a dar atenção para a relação, já que, para poder ser pessoa, precisa se relacionar com as coisas e o mundo e ultrapassá-los. Portanto, o sentido agora é buscado na relação, no entre, na mediação corpo-mundo.

Merleau-Ponty procura compreender a relação entre consciência perceptiva e a consciência representativa, e se esta não anula aquela. Para ele, segundo Chaui (1989, p. XI), “a consciência perceptiva é fundante com relação à representativa, de sorte que esta continua, no nível puramente intelectual, um conhecimento originado no nível sensível”. Desenvolve a ideia de uma “consciência perceptiva solidária com o corpo, enquanto corpo próprio ou vivido, maneira pela qual nos instalamos no mundo, ganhando e doando significação" (Chaui, 1989, p. XI). Corpo passa então a ser visto como reflexividade, mas também como visibilidade: "o corpo é o visível que 
se vê, um tocado que se toca, um sentido que se sente" (Chaui, 1989, p. XI). Essa interação é tão forte que, quando por exemplo,

(...) a mão direita toca a mão esquerda, há um acontecimento observável cuja peculiaridade é a ambigüidade: como determinar quem toca e quem é tocado? A descoberta do corpo reflexivo e observável leva Merleau-Ponty a mostrar que a experiência inicial do corpo consigo mesmo é uma experiência em propagação e que se repete na relação com as coisas e na relação com os outros (Chaui, 1989, p. XI).

Ao eleger a experiência corporal como originária, Merleau-Ponty evidencia a unidade do mundo como mundo sensível. Institui aí a intersubjetividade, negada tanto pelo racionalismo quanto pelo empirismo e o positivismo. Nessa perspectiva filosófica, "corpo e mundo são um 'campo de presença' onde emergem todas as relações da vida perceptiva e do mundo sensivel. Há um logos do mundo estético, um campo de significações sensíveis constituintes do corpo e do mundo" (Chaui, 1989, p. XII). É esse logos do mundo estético que, segundo MerleauPonty, possibilita a intersubjetividade como intercorporeidade que, por intermédio da manifestação corporal na linguagem, realiza a comunicação com os outros e com o mundo, criando-se, assim, o logos cultural, o "mundo humano da cultura e da história” (Chaui, 1989, p. XII). Marilena Chaui (1989, p. XII) afirma que é por isso que, para Merleau-Ponty,

(...) ciência e a filosofia da consciência são incapazes de demonstrar a possibilidade da relação intersubjetiva, na medida em que para a primeira cada um é um "amontoado de ossos, carne, sangue e pele" que se iguala a um autômato, a uma "coisa" ou matéria inerte, enquanto, para a segunda, é um "eu penso" único e total, não havendo como sair de si e encontrar o outro.

Cézanne queria pintar as coisas do jeito que ele as sentia, como o tato, o olfato, a audição, o paladar, o visual. Tomando essa experiência de Cézanne, Merleau-Ponty (1999, p. 208) afirma que "não é ao objeto físico que o corpo deve ser comparado, mas antes à obra de arte". Seja essa obra uma peça musical ou um quadro, não temos a apreensão apenas de um som ou de uma cor, mas o desdobramento de cores e sons. Quanto às obras de Cézanne, Merleau-Ponty (1945/1999, p. 208) afirma que,

(...) se não vi seus quadros, deixa-me a escolha entre vários Cézanne possíveis, e é a percepção dos quadros que me dá o único Cézanne existente, é nela que as análises adquirem seu sentido pleno. Assim como a obra de arte, o corpo-próprio é também "nó de significação", é fonte de sentidos. O corpo não é apenas objeto físico, mas também objeto simbólico, e "um visível que se vê, um tocado que se toca, um sentido que se sente".

Merleau-Ponty procura com isso encontrar o verdadeiro cogito, o que está inserido no mundo. Ao apontar a indissociabilidade entre mente e corpo, aponta também para a necessidade de o pensamento não ser posto fora do plano das ações, porque é a partir delas que ele se completa e se torna possível. A fala, por exemplo, não é posterior ao pensamento. Mais que reconhecer pensamento e ação como unidade, Merleau-Ponty procura mostrar que o agir tem seu pensamento: o olho olhando, a mão gesticulando, a palavra falando, o pensamento pensando. Todos esses gestos não são meras repetições mecânicas, mas pensamentos em plena realização. Por exemplo, a fala como poiesis é um projetar no-mundo, é um transcender e transcender-se é existir-para-o-mundo.

A partir dessas considerações, podemos dizer que, para Merleau-Ponty, o corpo tem ele mesmo seu pensar. Por isso, o corpo é fonte de sentidos. Para compreender, por exemplo, o gesto de cólera, não preciso, segundo Merleau-Ponty (1945/1999, p. 251), lembrar dos sentimentos que já experimentei de cólera: "o gesto não me faz pensar na cólera, ele é a própria cólera”. O gesto não é mais em-si, ele é comunicação, se distende para o mundo; é pensamento no mundo, muito mais do que pensamento $d o$ mundo; não é mais puramente tético, um para-si, mas um movimento de transcendência. A nossa ação é geradora de sentidos. Por isso ela pertence à dimensão da poiesis, da criação, é tessitura de expressividade.

\section{A Concepção de Existência no Pensamento de Merleau-Ponty}

Merleau-Ponty manifestou, em toda sua trajetória filosófica, a "sua perplexidade diante do mundo e o anseio constante em reaprender a ver este mundo" (Von Zuben, 2009, p. 1). Essa inquietação pode ser constatada em toda sua obra, mas de modo especial na conferência apresentada como aula inaugural ao assumir a cátedra de filosofia no Collège de France e que, depois, foi publicada com o título Elogio da filosofia, ao afirmar que o filósofo é "aquele que é testemunha da sua própria busca, isto é, da sua desordem interior" (Merleau-Ponty, 1953/1998, p. 9). Essa é uma atitude de espanto, páthos, diante dos outros e do mundo. E "o espanto é, enquanto páthos, a arché da filosofia. Devemos compreender, em seu pleno sentido, a palavra grega arché. Designa aquilo de onde algo surge" (Heidegger, 1956/1971, p. 36). Espanto significa paixão, mas é também, segundo Heidegger (1956/1971, p. 37), "deixar-se con-vocar por um apelo". Ser testemunha da sua própria "desordem interior" é deixar-se convocar pelo apelo da existência para compreendermos o seu sentido. A atitude de espanto e de desordem interior, de questionamento, de busca de sentido do mundo e da existência 
é a grande marca do pensamento filosófico merleau-pontyano. Para esse filósofo da existência, a tarefa da filosofia é contribuir para que possamos "reaprender a ver o mundo" (Merleau-Ponty, 1945/1999, p. 19), ver o mundo com os olhos humanizados; é a de colocar a existência como fundamento de todas as nossas ações.

No início do "Prefácio" à obra Fenomenologia da percepção, Merleau-Ponty (1945/1999, p. 3) apresenta a tarefa da fenomenologia quando afirma que ela visa ao retorno "às coisas mesmas", o que significa retorno à existência, ao mundo vivido, ao Lebenswelt (mundo da vida) proposto por Husserl, o que não é pura interioridade e nem pura exterioridade, mas mundo carnal e espiritual, objetivo e subjetivo, natural e cultural, mundo de significação. É por isso que ele afirma:

(...) eu não posso pensar-me como uma parte do mundo, como simples objeto da biologia, da psicologia e da sociologia, nem fechar sobre mim o universo da ciência. Tudo aquilo que sei do mundo, mesmo por ciência, eu o sei a partir de uma visão minha ou de uma experiência do mundo sem a qual os símbolos da ciência não poderiam dizer nada. Todo o universo da ciência é construído sobre o mundo vivido (MerleauPonty, 1945/1999, p. 3).

O “retorno às coisas mesmas" significa voltar-se para o mundo prévio a todo conhecimento, ao fenômeno em seu estado anterior a qualquer reflexão, ao mundo não tematizado, ao mundo vivido, ou seja, à existência prévia, e não à existência teorizada. $\mathrm{O}$ mundo de que MerleauPonty fala aqui não é o mundo da consciência, nem o mundo dos sentidos ou o conjunto dos dados empíricos, mas os horizontes mais concretos de nossa existência; é o mundo do trabalho, do lazer, da educação, da cultura, da política, da economia; mundo humanizado. É o mundo da percepção; mundo percebido, o mundo que envolve minha existência como um todo, a existência corporal, espiritual e suas manifestações; é o mundo que constitui o solo da nossa existência. É por isso que Merleau-Ponty (1945/1999, p. 6) afirma que:

(...) o mundo não é um objeto do qual possuo comigo a lei de constituição; ele é o meio natural e o campo de todos os meus pensamentos e de todas as minhas percepções explícitas. A verdade não "habita” apenas o "homem interior", ou, antes, não existe homem interior, o homem está no mundo, é no mundo que ele se conhece.

O mundo, nessa perspectiva, torna-se a base, o fundamento de todos os nossos pensamentos e de todas as nossas percepções. Para Husserl, mundo não são as coisas, pessoas, os minerais, animais, vegetais, o universo, existentes em si mesmos e que são transformados em objetos do conhecimento pela razão.
A razão é "doadora de sentido" e ela constitui a realidade não enquanto existência de seres, mas enquanto sistema de significações que dependem da estrutura da própria consciência. Ou, como explica Husserl, a realidade constituída pela consciência transcendental ou razão transcendental não se refere à existência de seres e sim a essências, isto é, a significações. As essências são verdadeiras, universais e necessárias porque são constituídas a priori pela própria razão. As significações ou essências são o conteúdo, pois a razão transcendental é doadora de sentido e o sentido é a única realidade existente para a razão (Chaui, 1989, p. 81-82).

Mundo e sentido são duas dimensões fundamentais da existência humana, "porque estamos no mundo, estamos condenados ao sentido, e não podemos fazer nada nem dizer nada que não adquira um nome na história" (Merleau-Ponty, 1945/1999, p. 18). O "retorno às coisas mesmas" é a recuperação do sentido do Lebenswelt. É pela redução eidética, a descrição, que apreendemos a consciência em sua manifestação originária, a sua abertura ao mundo e aos outros. É nesse sentido que MerleauPonty (1945/1999, p. 97) afirma que “a reflexão só é verdadeiramente reflexão se não se arrebata para fora de si mesma, se se conhece como reflexão-sobre-um-irrefletido e, por conseguinte, como uma mudança de estrutura de nossa existência".

Merleau-Ponty repõe as essências na existência, o que significa que o homem passa a ser compreendido a partir de sua facticidade, no seu contato com o mundo, onde ocorre a relação com o espaço, com o tempo, com o mundo vivido. A consciência perceptiva encontra-se imbricada na relação com o vivido. O homem encontra-se entrelaçado no mundo, mas não é por ele subsumido; está imerso no mundo, mas mantém também um distanciamento deste e de si mesmo. É neste distanciamento que o homem descobre o outro e outro o descobre. Aqui, o ego e o alter passam a ter sentido quando o homem se percebe como uma consciência entre outras consciências. Sempre estivemos diante do paradoxo do outro. Essa é uma questão que precisa ser enfrentada, pois,

(...) se o outro é verdadeiramente para si para além de seu ser para mim, e se nós somos um para o outro e não um e outro para Deus, é preciso que apareçamos um ao outro, é preciso que ele tenha e que eu tenha um exterior, e que exista, além da perspectiva do Para $\mathrm{Si}$ - minha visão sobre mim e a visão do outro sobre ele mesmo -, uma perspectiva do Para Outro - minha visão sobre o Outro e a visão do Outro sobre mim. Certamente, estas duas perspectivas, em cada um de nós, não podem estar simplesmente justapostas, pois então não seria a mim que o outro veria e não seria a ele que eu veria. É preciso que eu seja meu exterior, e 
que o corpo do outro seja ele mesmo. Esse paradoxo e essa dialética do Ego e do Alter só são possíveis se o Ego e o Alter são definidos por sua situação e não liberados de toda inerência, quer dizer, se a filosofia não se completa com o retorno ao eu, e se descubro pela reflexão apenas minha presença a mim mesmo mas também a possibilidade de um "espectador estrangeiro", quer dizer, se também, no próprio momento em que experimento minha existência, e até nesse cume extremo da reflexão, eu careço ainda desta densidade absoluta que me faria sair do tempo, e descubro em mim um tipo de fraqueza interna que me impede de ser absolutamente indivíduo e me expõe ao olhar dos outros como um homem entre os homens, ou pelo menos uma consciência entre as consciências. Até hoje, o Cogito desvalorizava a percepção de um outro, ele me ensinava que o Eu só é acessível a si mesmo, já que ele me definia pelo pensamento único a ter, pelo menos nesse sentido último. Para que outro não seja uma palavra vã, é preciso que minha existência envolva também a consciência que dele se possa ter e, portanto, minha encarnação em uma natureza e pelo menos a possibilidade de uma situação histórica. O cogito deve revelar-me em situação, e é apenas sob essa condição que a subjetividade transcendental poderá, como diz Husserl, ser uma intersubjetividade (Merleau-Ponty, 1945/1999, p. 8-9).

A citação acima, apesar de ser longa, nos ajuda a entender que o cogito não é mais um cogito isolado do mundo e dos outros, mas em situação, e é nesta condição que a subjetividade se manifesta em intersubjetividade. A existência se torna a própria essência do homem: não há homem sem mundo, nem mundo sem homem; não há consciência sem objeto, nem objeto sem consciência. O homem é parte do tecido da tessitura do mundo que ele habita.

\section{Em Busca de Sentidos Formativos}

Podemos dizer que essas concepções merleau-pontyanas sobre corpo e existência apresentam um sentido, sobretudo, formativo. A educação nessa perspectiva precisa ser compreendida como formação, e não como instrumentalização. A instrumentalização transforma o ato de ensinar em um ato mecânico, cuja preocupação é com a memorização, a reprodução, a impessoalização, a burocratização, a técnica e a negação do mundo vivido. Instrumentalizar é, portanto, o ato de transformar uma atividade que é eminentemente humana, expressão de criação, de liberdade, de sensibilidade, de criticidade, de autonomia, em um meio técnico, objetivo e calculista. A atividade educativa assim orientada perde sua humanidade, se reduz a uma coisa, a um instrumento, reifica-se, perde sua capacidade de inventividade. Já a for- mação é entendida como processo humanizador, como devir civilizatório, humanização do homem e do mundo. A formação, nesse sentido, assemelha-se ao ideal educativo grego, à paidéia, formação do estado de espírito em que se desabrocham todas as virtualidades humanas. É por isso que, segundo Werner Jaeger (1936/2001, p. 7), os gregos denominaram paidéia todas as formas e criações espirituais e a sua tradição: "foi sob a forma de paidéia, de 'cultura', que os gregos consideraram a totalidade da sua obra criadora".

A formação é assim entendida como formação cultural, que é formação para a liberdade e para a autonomia; é uma formação aberta, ampla, que valoriza o domínio teórico, o desenvolvimento da sensibilidade artística e cultural, o espírito da dúvida e da crítica, a preparação para o mundo do trabalho e o desenvolvimento corporal. Se o corpo não é uma "coisa", mas fonte de sentido, como afirmou Merleau-Ponty, então a educação escolar que compreende o homem como ser-no-mundo é importante para a pessoa descobrir a si próprio, os outros e o mundo; é uma importante contribuição para que a pessoa desenvolva as suas próprias habilidades corporais e intelectuais.

A educação, a partir dessa orientação, ajuda a compreender que o corpo não é uma coisa, nem uma ideia, mas movimento, sensibilidade e expressão criativa. MerleauPonty contribui para a compreensão do corpo como corporeidade, como movimento, comunicação, unidade mente-corpo e fonte de sentido. Ele ressalta a experiência corporal fundada na perspectiva sensível e poética da corporeidade, visando superar a dicotomia sujeito/objeto. Ao dizer que sou "meu corpo", quer dizer que a subjetividade coincide com os processos corporais. "Ser corpo é estar atado a um certo mundo", o que significa que a dimensão essencial só revela sentido se estiver também atada à dimensão existencial, donde essência e existência apresentam-se como expressões de um mesmo fenômeno: o ser humano.

Pensar a educação na perspectiva da fenomenologia de Merleau-Ponty é pensá-la para além das velhas práticas pedagógicas que enfatizam o trabalho técnico separado do expressivo, e romper com as práticas educativas que ignoram o desenvolvimento da corporeidade.

A educação não deve considerar o desenvolvimento da pessoa de modo linear, como acontece com a orientação que adota a teoria do reflexo (estímulo-resposta). Para Merleau-Ponty, o desenvolvimento não é um contínuo, nem o hábito é soma de reflexos. A educação não pode também entender o desenvolvimento como mera tomada de consciência por um direcionamento de atos de ideação que intervêm na ruptura com o que precede. Para a concepção merleau-pontyana, não se trata de optar por um dos polos, mas pela mediação, o que está entre; o que interessa é a compreensão do sentido que aí ocorre. 


\section{Considerações Finais}

Merleau-Ponty foi um filósofo inquieto com os problemas da existência humana. Procurou romper com as concepções que dicotomizam o homem e o conhecimento. Rejeitou se filiar a qualquer polaridade, por entender que essa atitude empobrece a compreensão do homem e do mundo. Por isso, fez a opção epistemológica e política de valorizar as mediações e buscar aí a compreensão do sentido da existência humana. Ao colocar o corpo e a existência como uma das temáticas centrais do seu pensamento e compreendê-los como unidade de sentidos, trouxe enormes contribuições para se ressignificar a formação humana. Há muito que se explorar dessas contribuições de Merleau-Ponty para a educação. Está aí o desafio para alargarmos os horizontes da formação humana com as contribuições merleau-pontyanas.

\section{Referências}

Chaui, M. (1989). Merleau-Ponty: vida e obra. In: Merleau-Ponty (Coleção Os Pensadores). São Paulo: Nova Cultural.

Coelho Jr., N. \& Carmo, P. S. (1991). Merleau-Ponty: filosofia como corpo e existência. São Paulo: Escuta.

Heidegger, M. (1971). O que é isto - a filosofia?: identidade e diferença. São Paulo: Livraria Duas Cidades (original publicado em 1956).

Husserl, E. (2001). Meditações cartesianas: introdução à fenomenologia. São Paulo: Madras (original publicado em 1929).

Jaeger, W. (2001). Paidéia: a formação do homem grego. São Paulo: Martins Fontes (original publicado em 1936).
Merleau-Ponty, M. (1998). Elogio da filosofia. Lisboa: Guimarães Editores (original publicado em 1953).

Merleau-Ponty, M. (1999). Fenomenologia da percepção. São Paulo: Martins Fontes (original publicado em 1945).

Peixoto, A. J. (2003). A origem e os fundamentos da fenomenologia: uma breve incursão pelo pensamento de Husserl. Em Adão José Peixoto (Org.). Concepções sobre fenomenologia [pp. 13-32]. Goiânia: Editora UFG.

Peixoto, A. J. (2011). Corpo e existência em Merleau-Ponty. Em Carlos Diógenes Côrtes Tourinho \& Maria Aparecida Viggiani Bicudo (Orgs.). Fenomenologia: influxos e dissidências [pp. 156-168]. Rio de Janeiro: Booklink.

Von Zuben, N. A. (2009). Fenomenologia e existência: uma leitura de Merleau-Ponty. Disponível em: www.fae.UNICAMP. br/vonzuben/fenom.html.

Zilles, U. (2003). Teoria do conhecimento. Porto Alegre: EDIPURCS.

Adão José Peixoto - Mestre em Filosofia (PUC-Campinas), Doutor em Educação pela Universidade de São Paulo (USP), Professor da Faculdade de Educação da Universidade Federal de Goiás, nos cursos de Graduação (Pedagogia) e Pós-Graduação Stricto Sensu (Mestrado e Doutorado) em Educação. Endereço Institucional: Universidade Federal de Goiás, Faculdade de Educação, Departamento de Fundamentos da Educação. Rua Delenda Rezende de Melo, Setor Universitário. CEP 74605-050. E-mail: peixotoufg@hotmail.com

Recebido em 01.07.2011

Primeira Decisão Editorial em 05.10.11

Aceito em 15.02.12 